\title{
Dynamic Passive Dosing for Studying the Biotransformation of Hydrophobic Organic Chemicals: Microbial Degradation as an Example
}

Smith, Kilian E. C.; Rein, Arno; Trapp, Stefan; Mayer, Philipp; Karlson, Ulrich Gosewinkel

Published in:

Environmental Science \& Technology (Washington)

Link to article, DOI:

10.1021/es204050u

Publication date:

2012

Document Version

Publisher's PDF, also known as Version of record

Link back to DTU Orbit

Citation (APA):

Smith, K. E. C., Rein, A., Trapp, S., Mayer, P., \& Karlson, U. G. (2012). Dynamic Passive Dosing for Studying the Biotransformation of Hydrophobic Organic Chemicals: Microbial Degradation as an Example. Environmental Science \& Technology (Washington), 46(9), 4852-4860. https://doi.org/10.1021/es204050u

\section{General rights}

Copyright and moral rights for the publications made accessible in the public portal are retained by the authors and/or other copyright owners and it is a condition of accessing publications that users recognise and abide by the legal requirements associated with these rights.

- Users may download and print one copy of any publication from the public portal for the purpose of private study or research.

- You may not further distribute the material or use it for any profit-making activity or commercial gain

- You may freely distribute the URL identifying the publication in the public portal 


\title{
Dynamic Passive Dosing for Studying the Biotransformation of Hydrophobic Organic Chemicals: Microbial Degradation as an Example
}

\author{
Kilian E. C. Smith, ${ }^{* \dagger}$ Arno Rein, ${ }^{\ddagger}$ Stefan Trapp, ${ }^{\ddagger}$ Philipp Mayer, ${ }^{\dagger}$ and Ulrich Gosewinkel Karlson ${ }^{\dagger}$ \\ ${ }^{\dagger}$ Department of Environmental Science, Aarhus University, Frederiksborgvej 399, P.O. Box 358, 4000 Roskilde, Denmark \\ ${ }^{\ddagger}$ Department of Environmental Engineering, Technical University of Denmark, Miljøvej building 113, 2800 Kgs. Lyngby, \\ Denmark
}

\section{Supporting Information}

ABSTRACT: Biotransformation plays a key role in hydrophobic organic compound (HOC) fate, and understanding kinetics as a function of (bio)availability is critical for elucidating persistence, accumulation, and toxicity. Biotransformation mainly occurs in an aqueous environment, posing technical challenges for producing kinetic data because of low HOC solubilities and sorptive losses. To overcome these, a new experimental approach based on passive dosing is presented. This avoids using cosolvent for introducing the HOC substrate, buffers substrate depletion so biotransformation is measured within a narrow and defined dissolved concentration range, and enables high compound turnover even at low concentrations to simplify end point measurement. As a case study, the biodegradation kinetics of two model HOCs by the bacterium Sphingomonas paucimobilis EPA505 were measured at defined dissolved concentrations ranging over 4 orders of magnitude, from 0.017 to $658 \mu \mathrm{g} \mathrm{L}-1$ for phenanthrene and from 0.006 to $90.0 \mu \mathrm{g} \mathrm{L}$ for fluoranthene. Both compounds had similar mineralization fluxes, and these increased by 2 orders of magnitude with increasing dissolved concentrations. First-order mineralization rate constants were also similar for both PAHs, but decreased by around 2 orders of magnitude with increasing dissolved concentrations. Dynamic passive dosing is a useful tool for measuring biotransformation kinetics at realistically low and defined dissolved HOC concentrations.

\section{INTRODUCTION}

Biotransformation plays a key role in hydrophobic organic compound (HOC) fate in different scenarios, including microbial degradation ${ }^{1,2}$ and metabolism in organisms with implications for bioaccumulation ${ }^{3-5}$ or the production of toxic metabolites. $^{6,7}$ Therefore, measuring biotransformation as a function of (bio)availability is critical for understanding their persistence, accumulation, or toxicity. The most common approach for determining HOC biotransformation kinetics is substrate depletion. Here, a defined mass of HOC substrate is added and the biotransformation kinetics inferred from the measured substrate decrease, metabolite production, or, in the case of microbial degradation, biomass production., ${ }^{3,8-12}$

However, biotransformation occurs in an aqueous environment, posing technical challenges for producing reliable experimental kinetic data for HOCs. Their hydrophobicity means they are problematic to dissolve and have a propensity to sorb, making it difficult to initially establish well-defined dissolved concentrations. Furthermore, their low aqueous solubilities mean that only small concentrations are present in the aqueous phase, posing analytical challenges when measuring changes, particularly at environmentally realistic concentrations, which can be orders of magnitude below aqueous solubility. Also, inherent in the substrate depletion approach is the progressive consumption of substrate, such that the biotransforming cells or enzymes are exposed to concentrations that decrease by orders of magnitude. Therefore, to overcome these limitations new experimental approaches are required which should (1) avoid using cosolvent for introducing the HOC substrate, (2) provide well-defined freely dissolved concentrations ranging from aqueous solubility down to zero, (3) buffer substrate depletion to allow measurement within a narrow range in concentrations, and (4) enable high compound turnover even at very low dissolved concentrations. In this regard, passive dosing can play a useful role (Figure 1).

In passive dosing, a dominating HOC reservoir dissolved in an inert polymer is introduced and the dissolved concentrations are then determined by partitioning such that these are defined even in the face of sorption and abiotic losses (requirements 1 and 2). By varying concentrations in the polymer, the

Received: November 13, 2011

Revised: $\quad$ March 29, 2012

Accepted: March 29, 2012

Published: March 29, 2012 


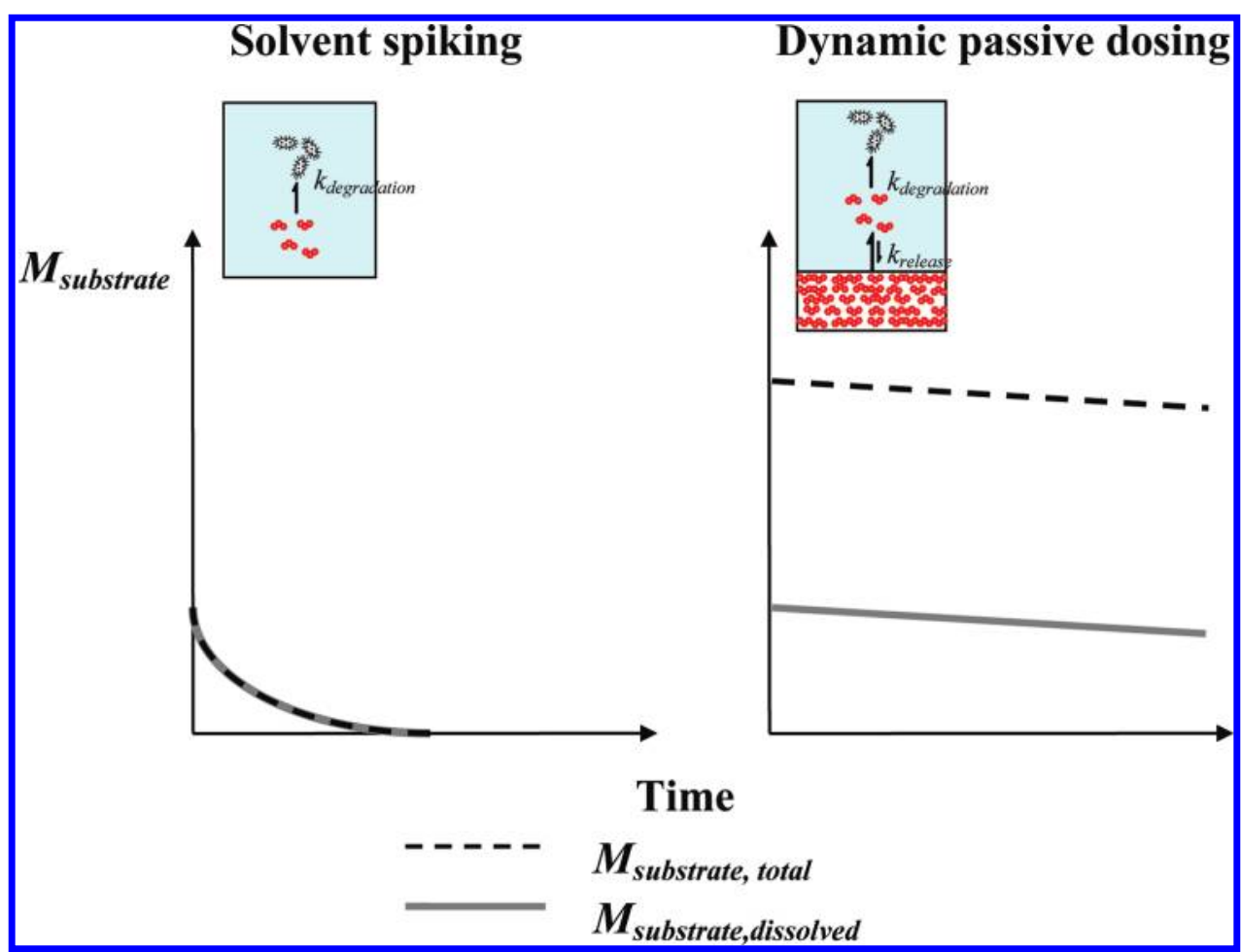

Figure 1. Solvent spiking and dynamic passive dosing for studying the biotransformation of hydrophobic compounds $(k$ stands for the first-order rate constant and $M$ for the mass of hydrophobic substrate). With passive dosing the large reservoir of hydrophobic substrate dissolved in a biocompatible polymer buffers the decrease in aqueous dissolved concentrations, so that biotransformation kinetics are determined within a tightly defined range.

dissolved concentrations can be controlled from aqueous solubility down to zero. High HOC solubility in the polymer means that a large mass of test compound is introduced, buffering substrate depletion even with high turnover in the aqueous phase (requirement 3 ). The high HOC partitioning ratio between the polymer and dissolved phases means significant turnover can be achieved even at very low dissolved concentrations (requirement 4). Passive dosing has been applied for the control of HOC exposure in toxicity, ${ }^{13-15}$ bioaccumulation, ${ }^{16}$ and speciation ${ }^{17}$ studies. However, the correct application of passive dosing to measure biotransformation kinetics requires that the format be properly optimized. Biotransformation will deplete the substrate, and the size of the HOC polymer reservoir should be dimensioned to keep this within acceptable limits. Furthermore, HOC release from the polymer should be sufficiently fast relative to the biotransformation kinetics such that steady-state dissolved concentrations are reliably defined with reference to the equilibrium partitioning levels.

This study demonstrates the application of dynamic passive dosing to measure HOC biotransformation kinetics. As a case study, the degradation of phenanthrene and fluoranthene by the bacterium Sphingomonas paucimobilis EPA505 was measured at defined dissolved concentrations in a miniaturized setup using silicone O-rings as the dosing polymer. Biodegradation kinetics were followed by measuring the evolution of ${ }^{14} \mathrm{CO}_{2}$ at dissolved concentrations ranging over 4 orders of magnitude, from 0.017 to $658 \mu \mathrm{g} \mathrm{L}^{-1}$ for phenanthrene and from 0.006 to $90.0 \mu \mathrm{g} \mathrm{L}^{-1}$ for fluoranthene. Finally, the wider application of dynamic passive dosing as a research platform to study HOC biotransformation is discussed.

\section{MATERIALS AND METHODS}

Chemicals and materials as well as the O-ring loading procedure and its validation are described in the Supporting Information. All loading and experiments were done at $21^{\circ} \mathrm{C}$.

Silicone O-Ring Passive Dosing Format. Silicone has advantages as a passive dosing phase including biocompatibility, high capacity for HOCs, low internal mass transfer resistance to HOCs, and it is cheaply available in different formats. The HOC mass required for loading the silicone and the speed of depletion both depend on the size of the silicone reservoir. To economize on the use of ${ }^{14} \mathrm{C}$ substrate, a silicone O-ring format was selected to optimize this balance. These are also practical to handle and have a good passive dosing performance, ${ }^{15}$ but of course, the format can be tailored according to the specific study requirements.

Culturing of the Bacteria. S. paucimobilis EPA505 was chosen since it degrades both phenanthrene and fluoranthene. ${ }^{18}$ For culturing purposes, polydimethylsiloxane (PDMS) silicone $(5 \mathrm{~g}$ ) was cast into the base of $60 \mathrm{~mL}$ brown glass jars and loaded to saturation with fluoranthene by partitioning from a methanol suspension for $48 \mathrm{~h}^{14}$ The loading solution was decanted, surfaces were wiped using lint-free tissue, and residual methanol was washed away by three sequential washes with $20 \mathrm{~mL}$ of Milli-Q water.

Preparation of Strain EPA505 Aliquots. To ensure that the biodegradation characteristics of the biomass were similar between experiments, identical aliquots from a stock culture were prepared. Strain EPA505 from a frozen supply was plated on LB agar plates and incubated at $30{ }^{\circ} \mathrm{C}$. A single colony was picked to inoculate a jar with fluoranthene-saturated PDMS and containing $50 \mathrm{~mL}$ of minimal salts medium. ${ }^{19}$ This was closed loosely with a foil-lined lid and placed on a horizontal shaker at 
$21{ }^{\circ} \mathrm{C}$ and $110 \mathrm{rpm}$. After growing for 4 days, $0.5 \mathrm{~mL}$ aliquots of the medium containing the grown biomass were dispensed into $1.5 \mathrm{~mL}$ Eppendorf vials and frozen at $-80{ }^{\circ} \mathrm{C}$. The remaining medium was streaked onto $\mathrm{LB}$ agar plates and incubated at $30{ }^{\circ} \mathrm{C}$, with only the typical colonies of strain EPA505 being observed.

Strain EPA505 Biomass Production. To produce biomass for the different experiments, $30 \mathrm{~mL}$ of minimal salts medium was added to a jar with fluoranthene-saturated PDMS and it was inoculated with $200 \mu \mathrm{L}$ of a thawed aliquot of strain EPA505. This aliquot was also streaked onto LB agar plates and incubated at $30^{\circ} \mathrm{C}$, and only the typical strain EPA505 colonies observed. The jar was closed with a foil-lined lid and placed on a horizontal shaker at $21^{\circ} \mathrm{C}$ and $110 \mathrm{rpm}$. After exactly 7 days, $5 \mathrm{~mL}$ of the grown biomass suspension was diluted with $45 \mathrm{~mL}$ of minimal salts medium for direct inoculation of the experiments. This suspension was also serially diluted and plated on LB agar plates for counting to give the initial biomass concentrations, and only typical strain EPA505 colonies were observed. Finally, a suspension sample was diluted 1:1 with methanol for HPLC analysis and fluoranthene was below detection limits $\left(<100 \mathrm{ng} \mathrm{L}^{-1}\right)$, showing carryover into the setups to be insignificant.

Experiments. Abiotic Release Kinetics of Fluoranthene. O-rings were loaded to saturation by partitioning for $72 \mathrm{~h}$ from a methanol solution containing excess fluoranthene (see Supporting Information), translating into equilibrium partitioning concentrations in the aqueous phase close to solubility. ${ }^{15}$ A single O-ring was placed in the bottom of each $4 \mathrm{~mL}$ brown glass vial together with a glass insert (see Figure S1 of the Supporting Information; hereafter termed passive dosing vial). The experiment was started by adding $1 \mathrm{~mL}$ of Milli-Q water to each vial and placing these on a vortex shaker (IKA Vibrax VXR basic, IKA Werke GmbH \& Co. KG, Staufen, Germany) at 100, 500 , or $1000 \mathrm{rpm}(n=3 \mathrm{each})$. At intervals, $30 \mu \mathrm{L}$ water samples were taken and added to $30 \mu \mathrm{L}$ of $\mathrm{MeOH}$ before analyzing by HPLC. Aqueous concentrations were plotted versus time and fitted with eq 1 below to determine the release rate constant $k_{\text {release }}\left(\mathrm{h}^{-1}\right)$.

Attachment of Strain EPA505 to the Silicone Surface. Attachment of strain EPA505 bacterial cells to the O-ring surface was quantified. A series of passive dosing vials containing cleaned but unloaded O-rings were prepared, and $1 \mathrm{~mL}$ of strain EPA505 inoculating suspension was added $\left(3.5 \times 10^{7} \mathrm{cfu} \mathrm{mL}{ }^{-1}\right.$, SD $\left.6.3 \times 10^{6}, n=3\right)$. The vials were closed and placed on a vortex shaker at $21{ }^{\circ} \mathrm{C}$ and $500 \mathrm{rpm}$. At $0,1.5,3.2,4.5,6,9,12,24$, and $31.7 \mathrm{~h}$, duplicate vials were sacrificed and $0.5 \mathrm{~mL}$ of the suspension added to a $1.5 \mathrm{~mL}$ Eppendorf vial with $200 \mu \mathrm{L}$ of glutaraldehyde. After staining with acridine orange and filtering serial dilutions on cellulose acetate filters, these were counted by epifluorescence microscopy. Bacteria adhering to the O-rings were counted directly on the surface after staining with acridine orange.

Passive Dosing Biodegradation Pilot Study. Phenanthrene was selected for the initial investigations because its silicone to water partitioning is lower than that of fluoranthene, meaning the silicone has a lower buffering capacity. O-rings were loaded with phenanthrene by spiking (see Supporting Information) to an initial silicone concentration of $50.07 \mathrm{mg} \mathrm{L}^{-1}$ (20000 dpm per O-ring), representing an equilibrium dissolved concentration of $8.66 \mu \mathrm{g} \mathrm{L}^{-1}$ (Table S1, Supporting Information). The biodegradation experiments were started by adding $1 \mathrm{~mL}$ of strain EPA505 culture $\left(3.5 \times 10^{7} \mathrm{cfu} \mathrm{mL}^{-1}, \mathrm{SD} 6.3 \times 10^{6}, n=3\right)$ and a glass insert with $200 \mu \mathrm{L}$ of $1 \mathrm{M} \mathrm{KOH}$ and placing the passive dosing vials on a vortex shaker at $500 \mathrm{rpm}$.

At $0,1.5,3.2,4.5,6,9,12,24$, and $31.7 \mathrm{~h}$, the $\mathrm{KOH}$ was replaced and added to $4.8 \mathrm{~mL}$ of Milli-Q water and $5 \mathrm{~mL}$ of Ready Gel for quantifying ${ }^{14} \mathrm{CO}_{2}$ by liquid scintillation counting. At 6, 12, and $31.7 \mathrm{~h}$, duplicate vials were sacrificed. The ${ }^{14} \mathrm{C}$ activity in the suspension was counted after mixing with $3.1 \mathrm{~mL}$ of Milli-Q water, $1 \mathrm{~mL}$ of methanol, and $5 \mathrm{~mL}$ of Ready Gel. The O-rings were quantitatively extracted overnight in $15 \mathrm{~mL}$ of methanol, and a $1 \mathrm{~mL}$ aliquot was mixed with $4 \mathrm{~mL}$ of Milli-Q and $5 \mathrm{~mL}$ of Ready Gel for liquid scintillation counting.

Biodegradation versus Dissolved Concentrations. Batches of O-rings were loaded with either phenanthrene or fluoranthene by spiking (see Supporting Information), to give silicone and equilibrium dissolved concentrations from near to saturation to a 10000 times dilution of this. Initial phenanthrene concentrations in the O-ring silicone were 4998, 499.9, 50.07, 5.16, and $0.66 \mathrm{mg} \mathrm{L}^{-1}\left(\left[9_{-}{ }^{14} \mathrm{C}\right]\right.$ phenanthrene, $20000 \mathrm{dpm}$ per O-ring), representing calculated equilibrium dissolved concentrations of $865,86.5,8.66,0.893$, and $0.115 \mu \mathrm{g} \mathrm{L}^{-1}$ (Table S1, Supporting Information). Initial fluoranthene concentrations in the O-ring silicone were 2259, 226.1, 22.78, 2.48, and $0.45 \mathrm{mg} \mathrm{L}^{-1}$ $\left(\left[3-{ }^{14} \mathrm{C}\right]\right.$ fluoranthene, $20000 \mathrm{dpm}$ per O-ring), representing calculated equilibrium dissolved concentrations of 141, 14.1, 1.42, 0.155, and $0.028 \mu \mathrm{g} \mathrm{L}^{-1}$ (Table S1, Supporting Information). Triplicate passive dosing vials were prepared for each concentration, and the biodegradation experiments were started by adding $1 \mathrm{~mL}$ of strain EPA505 suspension $\left(4.31 \times 10^{8} \mathrm{cfu} \mathrm{mL} \mathrm{mL}^{-1}\right.$, SD $\left.2.25 \times 10^{7}, n=5\right)$ and a glass insert containing $200 \mu \mathrm{L}$ of $1 \mathrm{M} \mathrm{KOH}$ and placing the vials on a vortex shaker at $500 \mathrm{rpm}$.

Two controls were included: (i) $1 \mathrm{~mL}$ of strain EPA505 inoculating suspension in passive dosing vials containing blank O-rings to account for chemical contamination $(n=3)$ and (ii) $1 \mathrm{~mL}$ of minimal salts medium without any strain EPA505 in passive dosing vials containing O-rings loaded with phenanthrene (total concentration $50.07 \mathrm{mg} \mathrm{L}^{-1}, 20000 \mathrm{dpm}$ per O-ring) or fluoranthene (total concentration $22.78 \mathrm{mg} \mathrm{L}^{-1}$, $20000 \mathrm{dpm}$ per O-ring) to account for bacterial contamination ( $n=3$ each $)$.

At $0,3,6,9,21$, and $32 \mathrm{~h}$, the $\mathrm{KOH}$ was replaced and prepared for liquid scintillation counting as above. After the final $\mathrm{KOH}$ sampling, ${ }^{14} \mathrm{C}$ activity in the bacterial suspension and O-rings were measured as above.

Analysis. HPLC Analysis. PAH analysis was by fluorescence detection using an Agilent 1100 HPLC equipped with a G1321A FLD operated at $260 \mathrm{~nm}$ for excitation and 350, 420, 440, and $500 \mathrm{~nm}$ for emission. A $30 \mu \mathrm{L}$ sample was injected at $28{ }^{\circ} \mathrm{C}$ on a $\mathrm{CP}-\mathrm{EcoSpher} 4 \mathrm{PAH}$ column (Varian Inc., Palo Alto, CA), with methanol and water as the mobile phase (for full details see ref 15). Phenanthrene or fluoranthene concentrations were quantified using a nine-point external standard calibration curve with the HP Chemstation software (B.03.01, Agilent Technologies, Palo Alto, CA).

Scintillation Counting. After vigorous shaking and storing overnight in the dark, samples were counted with a program for ${ }^{14} \mathrm{C}$ measurements using a LS 1801 scintillation counter (Beckman).

Modeling of the Setup. The abiotic release of fluoranthene into water was described using a one-compartment 
model

$$
C_{\mathrm{d}}(t)=C_{\mathrm{d}(\mathrm{eq})}\left(1-\exp ^{-k_{\text {release }}{ }^{2}}\right)
$$

where $C_{\mathrm{d}}(t)\left(\mu \mathrm{g} \mathrm{L}^{-1}\right)$ is the dissolved concentration at time $t(\mathrm{~h}), C_{\mathrm{d}(\mathrm{eq})}\left(\mu \mathrm{g} \mathrm{L}^{-1}\right)$ the equilibrium dissolved concentration, and $k_{\text {release }}\left(\mathrm{h}^{-1}\right)$ the release rate constant. The data from the release experiment were fitted by the least-squares method using Graphpad Prizm 5 (San Diego, CA), giving estimates of the release rate constant and equilibrium concentration.

Mass transfer from silicone into the aqueous phase is controlled by diffusion within an aqueous diffusive boundary layer (BL). ${ }^{20-22}$ Therefore, provided the silicone surface area, aqueous volume, and mixing remain constant, $k_{\text {release }}$ can be further deconvoluted into ${ }^{23}$

$$
k_{\text {release }}=\frac{A}{V} v
$$

where $A\left(2.842 \times 10^{-4} \mathrm{~m}^{2}\right)$ is the O-ring surface area, $V(1 \times$ $\left.10^{-6} \mathrm{~m}^{3}\right)$ is the aqueous volume, and $v$ is the O-ring to water mass transfer velocity $\left(\mathrm{m} \mathrm{h}^{-1}\right)$.

As a quantitative measure of the time to reach a partitioning equilibrium in the abiotic release experiments, the time to reach $95 \%$ steady-state $\left(t_{95 \% \text { steady-state }} \mathrm{h}\right)$ was used

$$
t_{95 \% \text { steady-state }}=\frac{\ln 20}{k_{\text {release }}}
$$

For the biodegradation experiments, the mass balance for the aqueous phase is found by combining desorption and sorption from the O-ring with Michaelis-Menten enzyme kinetics.

$$
\frac{\mathrm{d} m_{\mathrm{d}}}{\mathrm{d} t}=1000 A v\left(\frac{C_{\mathrm{Si}}}{K_{\mathrm{Si}: \mathrm{d}}}\right)-1000 A v\left(C_{\mathrm{d}}\right)-\frac{v_{\max } C_{\mathrm{d}}}{K_{\mathrm{M}}+C_{\mathrm{d}}} X
$$

where $m_{\mathrm{d}}$ is the mass of PAH $(\mu \mathrm{g})$ in the dissolved phase, $C_{\mathrm{Si}}\left(\mu \mathrm{g} \mathrm{L}^{-1}\right)$ is the PAH concentration in the silicone O-ring, $K_{\mathrm{Si} d}$ $\left(\mathrm{L} \mathrm{L}^{-1}\right)$ is the silicone to water partitioning ratio, $C_{\mathrm{d}}\left(\mu \mathrm{g} \mathrm{L}^{-1}\right)$ is the dissolved concentration, and the factor 1000 converts the volume units of $\mathrm{m}^{3}$ from above into L. Separately measured $K_{\mathrm{Si}}$ values were $5778 \mathrm{~L} \mathrm{~L}^{-1}$ for phenanthrene and $15986 \mathrm{~L} \mathrm{~L}^{-1}$ for fluoranthene. The last term in eq 4a describes whole-cell MichaelisMenten degradation, where $v_{\max }[\mu \mathrm{g} \text { (number of degrading cells })^{-1}$ $\mathrm{h}^{-1}$ is the biomass-normalized maximum degradation velocity, $K_{\mathrm{M}}$ $\left(\mu \mathrm{g} \mathrm{L}^{-1}\right)$ is the value of $C_{\mathrm{d}}$ for half of $v_{\max }$ and $X$ (number of degrading cells) is the biomass in the setup.

In a setup with constant $C_{\mathrm{d}}$ and insufficient substrate for biomass production so that $X$ does not increase, eq 4 a can be reduced to the special case of

$$
\frac{\mathrm{d} m_{\mathrm{d}}}{\mathrm{d} t}=1000 A v\left(\frac{C_{\mathrm{Si}}}{K_{\mathrm{Si}: \mathrm{d}}}\right)-1000 A v\left(C_{\mathrm{d}}\right)-k_{\mathrm{deg}} m_{\mathrm{d}}
$$

where $k_{\mathrm{deg}}$ is the measured first-order biodegradation rate constant $\left(\mathrm{h}^{-1}\right)$ and is equivalent to $v_{\max } X /\left(K_{\mathrm{M}}+C_{\mathrm{d}}\right)$. Dividing eq $4 \mathrm{~b}$ by the aqueous volume $V$ gives

$$
\begin{aligned}
\frac{\mathrm{d} C_{\mathrm{d}}}{\mathrm{d} t} & =\frac{1000 A v}{V}\left(\frac{C_{\mathrm{Si}}}{K_{\mathrm{Si}: \mathrm{d}}}\right)-\frac{1000 A v}{V}\left(C_{\mathrm{d}}\right)-k_{\mathrm{deg}} C_{\mathrm{d}} \\
& =\frac{1000 A v}{V}\left(\frac{C_{\mathrm{Si}}}{K_{\mathrm{Si}: \mathrm{d}}}\right)-\left(\frac{1000 A v}{V}+k_{\mathrm{deg}}\right) C_{\mathrm{d}} \\
& =I-k_{\text {total }} C_{\mathrm{d}}
\end{aligned}
$$

with $I$ describing input into the aqueous phase $\left(\mu \mathrm{g} \mathrm{L}^{-1} \mathrm{~h}^{-1}\right)$ and $k_{\text {total }}$ giving the total removal from the aqueous phase $\left(\mathrm{h}^{-1}\right)$. For a constant $C_{\mathrm{Si}}$, the steady-state dissolved concentration $C_{\mathrm{d}, \text { steady state }}\left(\mu \mathrm{g} \mathrm{L}^{-1}\right)$ is reached when $\mathrm{d} C_{\mathrm{d}} / \mathrm{d} t=0$ and is given by

$$
C_{\mathrm{d}, \text { steady-state }}=\frac{I}{k_{\text {total }}}=\frac{\frac{1000 A v}{V}\left(\frac{C_{\mathrm{Si}}}{K_{\mathrm{Sid}}}\right)}{\left(\frac{1000 A v}{V}+k_{\mathrm{deg}}\right)}
$$

\section{RESULTS AND DISCUSSION}

Culturing of the Bacteria. The high compound turnover mediated by passive dosing means it is also a useful approach for producing bacterial biomass. Introducing the HOCs dissolved in a polymer ensures a physical separation between the substrate and biomass-containing aqueous phase, simplifying separation prior to inoculation. When grown on solid HOCs this can be tedious and lead to carryover in low-concentration experiments. The possibility of controlling the dissolved concentrations also makes it useful for culturing on toxic or inhibitory substrates.

Abiotic Release Kinetics of Fluoranthene. Figure S2 (Supporting Information) shows the release of fluoranthene from the O-rings into $1 \mathrm{~mL}$ of Milli-Q water. At 100, 500, and $1000 \mathrm{rpm}, k_{\text {release }}$ values were $0.981,4.899$, and $13.65 \mathrm{~h}^{-1}$, respectively. These translate into equilibration times (see eq 3 ) of 184,37 , and $13 \mathrm{~min}$, respectively. Increased shaking resulted in faster release kinetics due to a thinning of the aqueous BL. Note that the release kinetics of fluoranthene and phenanthrene are almost identical since $v$ in eq 2 is given by $D_{\mathrm{d}} / \delta_{\mathrm{d}}{ }^{23}$ where $D_{\mathrm{d}}$ the is molecular diffusion coefficient $\left(\mathrm{m}^{2} \mathrm{~h}^{-1}\right)$ and $\delta_{\mathrm{d}}$ the thickness of the diffusive aqueous $\mathrm{BL}(\mathrm{m})$. Phenanthrene and fluoranthene have similar $D_{\mathrm{d}}$ values of 2.11 and $2.00 \mathrm{~m}^{2} \mathrm{~h}^{-1}$, respectively, ${ }^{24}$ and thus $\delta_{\mathrm{d}}$ is very similar. ${ }^{25}$ Faster shaking increases diffusive mass transfer from the O-ring into the aqueous phase but also leads to harsher conditions for the degraders. Therefore, as a balance, shaking at $500 \mathrm{rpm}$ was used for the biodegradation experiments, but this can of course be chosen according to requirements.

Attachment of Strain EPA505 to the Silicone Surface. Figure S3 (Supporting Information) shows the results of the attachment experiment. Within $9 \mathrm{~h}$, only about $2 \%$ of the added bacteria remained in suspension. In parallel the numbers associated with the silicone surface increased, and by around $12 \mathrm{~h}$ the cells measured on the silicone surface had stabilized at around $10 \%$ of the initially added numbers. These were distributed as isolated cells over the surface (Figure S4, Supporting Information). Also shown in Figure S3 (Supporting Information) is the percentage of the initial cells numbers accounted for by the suspension and silicone-surface measurements. Within $3 \mathrm{~h}$ most of the bacterial cells were not present in either of these locations. Significant cell death can be discounted from the mineralization curves, where activity remained constant well beyond $3 \mathrm{~h}$ (see Figure 2, for example). It is likely that the majority of the bacteria were associated with other surfaces, such as the glass vial and insert. The implications of this distribution are discussed below.

Passive Dosing Biodegradation Pilot Study. The ${ }^{14} \mathrm{C}$ mass balance (sum of ${ }^{14} \mathrm{CO}_{2},{ }^{14} \mathrm{C}$ in suspension, and ${ }^{14} \mathrm{C}$ phenanthrene remaining in the $\mathrm{O}$-ring) at experiment completion was $102.1 \%$ (SD 4.3\%), indicating minimal losses and good reproducibility (Table S2, Supporting Information). Figure S5A (Supporting Information) shows the distribution of ${ }^{14} \mathrm{CO}_{2},{ }^{14} \mathrm{C}$ in suspension, and ${ }^{14} \mathrm{C}$ phenanthrene in the silicone after 6,12 , and $32 \mathrm{~h}$. With increasing time, larger proportions 


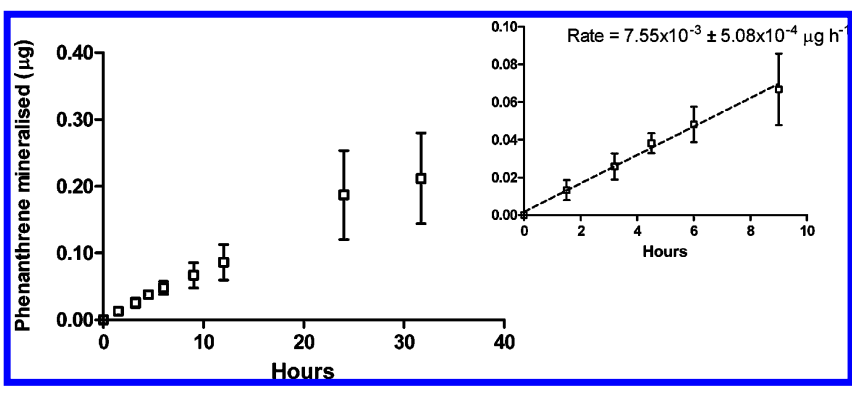

Figure 2. Cumulative mass of phenanthrene mineralized in the depletion experiment at a steady-state dissolved concentration of 4.57 $\mu \mathrm{g} \mathrm{L}^{-1}$. The insetted graph shows a blowup of the initial $9 \mathrm{~h}$, when the cumulative mineralization can be approximated by a linear function of time. The initial mineralization rate was calculated by linear regression of the data from the first $9 \mathrm{~h}$. Error bars give the standard deviation of measurements from the triplicate vials.

were found as ${ }^{14} \mathrm{CO}_{2}$ as well as ${ }^{14} \mathrm{C}$ in suspension, mirrored by a decrease of ${ }^{14} \mathrm{C}$ phenanthrene in the silicone. After 6, 12, and $32 \mathrm{~h}$ the silicone reservoir was depleted of phenanthrene by 0.8 , 8.9 , and 20.9\%, respectively. Figure S5B (Supporting Information) shows the relative distribution of ${ }^{14} \mathrm{C}$ in suspension as phenanthrene or biomass/metabolites and as ${ }^{14} \mathrm{CO}_{2}$. The masses of dissolved of phenanthrene as determined by equilibrium partitioning were negligible, with the majority of ${ }^{14} \mathrm{C}$ as biomass/metabolites in the suspension and as ${ }^{14} \mathrm{CO}_{2}$. The ratio $\left[{ }^{14} \mathrm{CO}_{2} /{ }^{14} \mathrm{C}\right.$ in suspension $\left.+{ }^{14} \mathrm{CO}_{2}\right]$ thus gives the mineralized fraction of the total mass degraded. Mineralization fractions were $0.22,0.20$, and 0.34 after 6,12 , and $32 \mathrm{~h}$, respectively (Figure S5B, Supporting Information).

The cumulative phenanthrene mineralization curve is shown in Figure 2, together with a blowup of the first $9 \mathrm{~h}$, where the flux is well-approximated by a linear function of time. Linear regression up to $9 \mathrm{~h}$ gives the initial mineralization flux, and this was normalized to the starting biomass $\left(3.5 \times 10^{7} \mathrm{cfu} \mathrm{mL}^{-1}\right)$ to give a specific initial mineralization flux of $2.19 \times 10^{-4} \mu \mathrm{g} \mathrm{h}^{-1}$ $\left(10^{6} \mathrm{cfu}\right)^{-1}$ (Table 1). The initial specific biodegradation flux was $1.10 \times 10^{-3} \mu \mathrm{g} \mathrm{h}^{-1}\left(10^{6} \mathrm{cfu}\right)^{-1}$ (Table 1), calculated using the initial mineralization flux and mineralization fraction of 0.20 measured at $12 \mathrm{~h}$. The steady-state dissolved concentration for the first $9 \mathrm{~h}$ was calculated using the abiotic release rate constant of $4.899 \mathrm{~h}^{-1}$ and initial degradation rate from above (see eq 6). This was $4.57 \mu \mathrm{g} \mathrm{L}^{-1}$ and equivalent to $53 \%$ of the equilibrium partitioning value (Table S1, Supporting Information). Specific first-order rate constants were calculated by normalizing the above mineralization and biodegradation fluxes to the calculated steady-state dissolved concentration and were $4.79 \times$ $10^{-2} \mathrm{~h}^{-1}\left(10^{6} \mathrm{cfu}\right)^{-1}$ for mineralization and $2.42 \times 10^{-1} \mathrm{~h}^{-1}$ $\left(10^{6} \mathrm{cfu}\right)^{-1}$ for degradation (Table 1$)$.

The cumulative phenanthrene mineralization curve displayed a gradual flattening with increasing time (Figure 2), indicating a progressive reduction in the mineralization fluxes. The initial flux over the first $9 \mathrm{~h}$ was compared to the final flux calculated for the period 24-31.7 h, with a decrease by a factor of 2.3 being observed. Reasons for this are discussed below.

Biodegradation versus Dissolved Concentrations. In the uninoculated controls no ${ }^{14} \mathrm{C}$ activity was found in suspension or as ${ }^{14} \mathrm{CO}_{2}$, and ${ }^{14} \mathrm{C}$ PAH was only measured in the O-ring (data not shown). In the blank O-ring controls ${ }^{14} \mathrm{C}$ was not detected in any phase (data not shown). Table S2 (Supporting Information) shows the ${ }^{14} \mathrm{C}$ mass balances for the different compounds and levels. Mean mass balances were 96\%

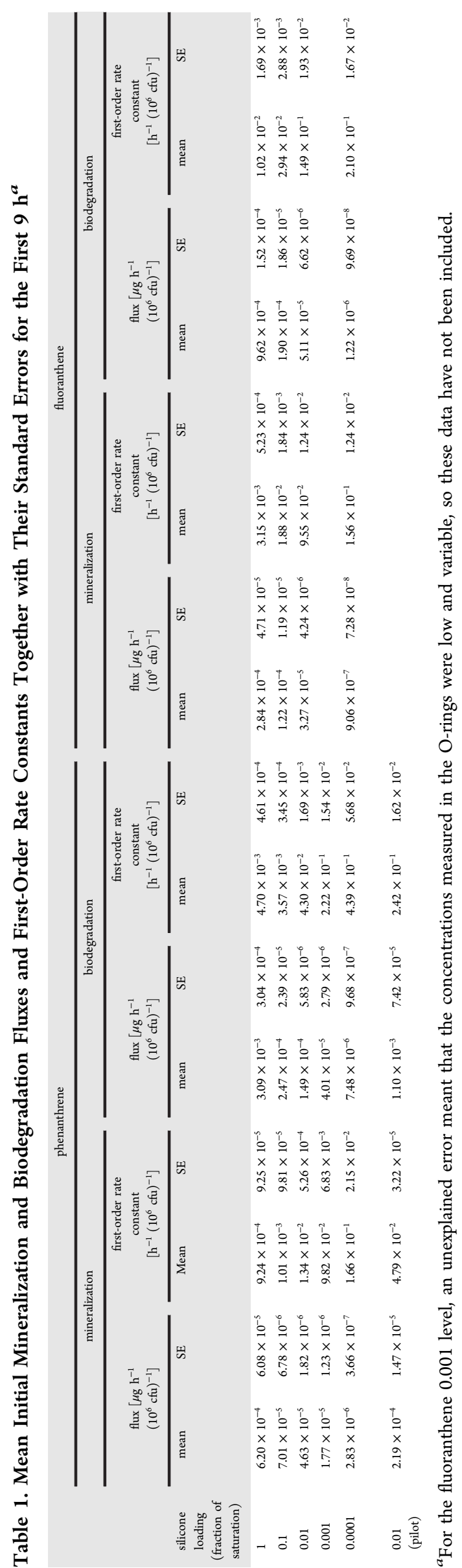


(range $81-109 \%$ ) for phenanthrene and 98\% (range 88$110 \%)$ for fluoranthene. For the $2.48 \mathrm{mg} \mathrm{L}^{-1}$ O-ring concentration of fluoranthene $(\times 0.001$ fraction of saturation $)$, the masses recovered in the O-rings were low and variable, indicating an error in the loading or extraction step. This treatment has not been included in the discussion below.

Depletion of the silicone at 9 and $32 \mathrm{~h}$ is shown in Table S3 (Supporting Information), with depletion consistently being higher at lower dissolved concentrations. Depletion after $9 \mathrm{~h}$ was between 1.4 and $26.3 \%$ for phenanthrene and lower at between 0.9 and $6.1 \%$ for fluoranthene. After $32 \mathrm{~h}$, depletion was correspondingly higher: for phenanthrene between 2.5 and $45.9 \%$ and for fluoranthene between 1.8 and $14.0 \%$. The fractions of the total mass of phenanthrene and fluoranthene degraded ending up as $\mathrm{CO}_{2}$ were also calculated. For phenanthrene these ranged between 0.20 and 0.44 , whereas for fluoranthene these were slightly higher at between 0.31 and 0.74 (Table S3, Supporting Information).

Specific mineralization fluxes were calculated using linear regression of the data up to $9 \mathrm{~h}$ (Figure S6a,b, Supporting Information) and normalizing to the initial biomass $\left(4.31 \times 10^{8}\right.$ $\left.\mathrm{cfu} \mathrm{mL}^{-1}\right)$. For phenanthrene these increased by a factor of 219 from $2.83 \times 10^{-6}$ to $6.20 \times 10^{-4} \mu \mathrm{g} \mathrm{h}^{-1}\left(10^{6} \mathrm{cfu}\right)^{-1}$ and for fluoranthene by a factor of 313 from $9.06 \times 10^{-7}$ to $2.84 \times$ $10^{-4} \mu \mathrm{g} \mathrm{h}^{-1}\left(10^{6} \mathrm{cfu}\right)^{-1}$ (Table 1 and Figure 3a). These were converted into initial specific biodegradation fluxes using the mineralization fractions given in Table S3 (Supporting Information) and ranged between $7.48 \times 10^{-6}$ and $3.09 \times$ $10^{-3} \mu \mathrm{g} \mathrm{h}^{-1}\left(10^{6} \mathrm{cfu}\right)^{-1}$ for phenanthrene and between $1.22 \times$ $10^{-6}$ and $9.62 \times 10^{-4} \mu \mathrm{g} \mathrm{h}^{-1}\left(10^{6} \mathrm{cfu}\right)^{-1}$ for fluoranthene (Table 1). Therefore, the calculated fluxes did not increase proportionally to the dissolved concentrations, i.e., a factor 10 increase in the concentrations did not lead to a factor ten increase in the fluxes. This is also evident from the total masses degraded after $9 \mathrm{~h}$ shown in Table S5 (Supporting Information). Although these increased at the higher concentrations, this was not by a constant factor and by less than the corresponding increase in dissolved concentrations. This implies that at higher concentrations mineralization and degradation were relatively less effective. It is not clear whether this is due to the maximum enzyme activity $v_{\max }$ being approached or due to other reasons, such as toxicity or limiting nutrient availability, at higher concentrations.

Calculated steady-state dissolved concentrations for the initial linear phase ranged between 15 and $80 \%$ for phenanthrene and between 21 and $64 \%$ for fluoranthene of the equilibrium partitioning values (Table S1, Supporting Information). These approached equilibrium values more closely at higher concentrations, in line with the lower biodegradation fluxes. Finally, the above fluxes were normalized to the calculated steady-state dissolved concentrations to give specific first-order rate constants (Table 1 and Figure $3 b$ ), and these decreased with increasing dissolved concentrations. Mineralization firstorder rate constants decreased by a factor of 176 from $1.66 \times$ $10^{-1}$ to $9.24 \times 10^{-4} \mathrm{~h}^{-1}\left(10^{6} \mathrm{cfu}\right)^{-1}$ for phenanthrene and by a factor of 50 from $1.56 \times 10^{-1}$ to $3.15 \times 10^{-3} \mathrm{~h}^{-1}\left(10^{6} \mathrm{cfu}\right)^{-1}$ for fluoranthene. The corresponding decrease in biodegradation first-order rate constants was by a factor of 93 from $4.39 \times 10^{-1}$ to $4.70 \times 10^{-3} \mathrm{~h}^{-1}\left(10^{6} \mathrm{cfu}\right)^{-1}$ for phenanthrene and by a factor of 21 from $2.10 \times 10^{-1}$ to $1.02 \times 10^{-2} \mathrm{~h}^{-1}\left(10^{6} \mathrm{cfu}\right)^{-1}$ for fluoranthene (Table 1). A direct comparison between the two PAHs is not possible, since the tested dissolved concentrations were not identical, but the overall trend was that the first-order

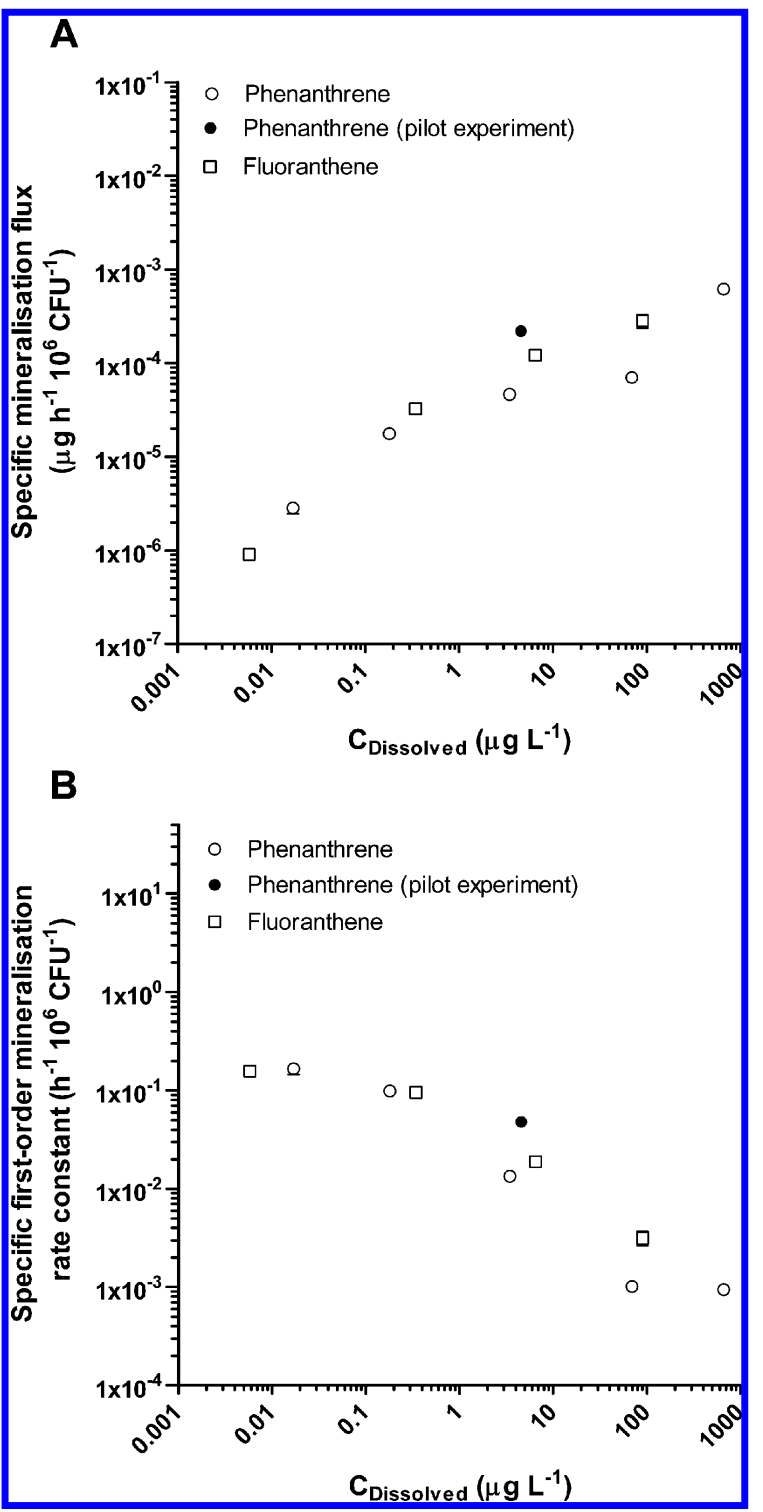

Figure 3. Phenanthrene and fluoranthene specific mineralization fluxes $\left[\mu \mathrm{g} \mathrm{h}^{-1}\left(10^{6} \mathrm{cfu}\right)^{-1}\right]$ from the pilot and biodegradation experiments (A), determined by linear regression of the initial $9 \mathrm{~h}$ of the cumulative mineralization curves. Specific first-order mineralization rate constants $\left[\mathrm{h}^{-1}\left(10^{6} \mathrm{cfu}\right)^{-1}\right](\mathrm{B})$, calculated by normalizing the above mineralization fluxes to the steady-state dissolved concentrations. Error bars give the standard error of the regression slope and are sometimes smaller than the symbols.

rate constants were slightly higher for fluoranthene. It might appear counterintuitive that despite the slightly higher rate constants observed for fluoranthene the depletion of the silicone was lower. However, this reflects the increased partitioning of the more hydrophobic fluoranthene to the silicone, such that it is a more efficient buffer.

Literature values for biodegradation kinetics are available from substrate depletion experiments, where dissolved concentrations have been modeled by taking sorption and abiotic losses into account. A study using a mixed enrichment culture and below aqueous solubility concentrations ${ }^{10}$ reported first-order biodegradation rate constants for phenanthrene of $2.70 \times 10^{-5} \mathrm{~h}^{-1}$ $\left(10^{6} \text { cells }\right)^{-1}$ and for fluoranthene of $3.2 \times 10^{-5} \mathrm{~h}^{-1}\left(10^{6} \text { cells }\right)^{-1}$. These were similar for both PAHs (as found in this study) but 
considerably lower probably due to differences in the degrading organisms. A study investigating the biodegradation of below aqueous solubility concentrations by the strain EPA505 ${ }^{11}$ reported first-order biodegradation rate constants of $4.18 \times$ $10^{-4} \mathrm{~h}^{-1}\left(10^{6} \text { cells }\right)^{-1}$ for phenanthrene and $5.92 \times 10^{-4} \mathrm{~h}^{-1}$ $\left(10^{6} \text { cells }\right)^{-1}$ for fluoranthene. These are lower than the values determined in this study, but the reasons are difficult to elucidate since there are fundamental differences in the depletion and dynamic passive dosing approaches. With the substrate depletion approach, biodegradation kinetics are inferred from the decrease in substrate mass and described by a single first-order rate constant. However, the effective concentrations decrease during the experiment. In contrast, with dynamic passive dosing, the biodegradation activity is measured at dissolved concentrations that are well-defined and relatively constant. Therefore, the measured rates can be related to a well-defined bioavailability metric, in this study given by the steady-state dissolved concentrations.

All cumulative mineralization curves showed a gradual flattening as the experiment progressed, indicating a progressive decrease in the mineralization fluxes (Figure S6a,b, Supporting Information). The initial fluxes over the first $9 \mathrm{~h}$ were compared to the final fluxes between 21 and $32 \mathrm{~h}$. For phenanthrene, the latter were 2.1-4.4 times lower, whereas for fluoranthene they were 1.2-2.7 times lower. Although these decreases were in general higher for phenanthrene, no trend could be determined with, for example, dissolved concentrations or total mass degraded. Data from initial tests with an increased sampling resolution showed this to be a gradual decrease (data not shown).

Progressive depletion of PAH in the silicone will lead to a concurrent decrease in dissolved concentrations and thus also the mineralization fluxes (see modeling section). However, $\mathrm{PAH}$ depletion of the silicone was less than $25 \%$ in all experiments (Table S3, Supporting Information), which cannot explain the observed decreases. The high permeability and solubility of the PAHs in the silicone means that mass exchange is controlled by diffusion in the aqueous $\mathrm{BL},{ }^{20-22}$ and thus no concentration gradients develop within the silicone that might lead to decreased mineralization. Oxygen limitations are also unlikely. The calculated mass of oxygen per vial was $28.4 \mu \mathrm{mol}$ $(0.5 \mu \mathrm{mol}$ in the $1 \mathrm{~mL}$ of water and $27.9 \mu \mathrm{mol}$ in the $3 \mathrm{~mL}$ of headspace). Table S5 (Supporting Information) shows the masses of PAHs degraded for the different experiments, and for these to be completely mineralized would require only $0.003-$ $1.57 \mu \mathrm{mol}$ of oxygen in the phenanthrene experiments and $0.0003-0.50 \mu \mathrm{mol}$ of oxygen in the fluoranthene experiments. Note also that the vials were opened to sample the $\mathrm{KOH}$, replenishing the headspace. Essential nutrients were initially present in excess in the medium. Furthermore, any effects of nutrient limitation should be more pronounced with an increase in the total amount mineralized, which was not observed. Similarly, the accumulation of toxic metabolites can be ruled out, since inhibition should also be more severe with increased mineralization. The $10 \%$ attachment of the bacterial cells to the silicone surface has a number of implications. A high percentage surface coverage could reduce the silicone surface area available for exchange or alter mass transfer to the bacterial cells. $^{26}$ However, the bacteria were sparsely distributed as isolated cells on the silicone surface (Figure S4, Supporting Information) such that any reduction in the substrate uptake flux is negligible. ${ }^{26}$ Furthermore, the temporal development in attachment (before $3 \mathrm{~h}$ ) does not tally in any way with the observed decrease in rates (after $9 \mathrm{~h}$ ). A reduction in $\mathrm{PAH}$ degradation capability, either because of cell death or inactivation of PAH catabolic machinery, could cause a decrease in rates. Starvation might be expected to be more pronounced at lower dissolved concentrations, where the masses degraded were lower (Table S4, Supporting Information), but this was not reflected in the measured decreases. In contrast, the intrinsic death rate of the degrading microbial population would impact all treatments equally and thus lead to a similar decrease in the fluxes, as was in fact observed. In any case, future efforts might be directed at investigating the underlying causes, with a view to further optimizing the passive dosing approach to study biotransformation in longer term experiments.

Steady-State Dissolved Concentrations. Knowledge of the dissolved concentrations that the biotransforming cells are exposed to is needed to understand bioavailability-rate relationships and calculate first-order rate constants. With passive dosing, dissolved concentrations can be precisely defined, which is particularly critical at very low concentrations, where direct analytical measurement is not feasible. However, this requires that setup properties do not change, i.e., minimal mass depletion in the polymer and constant biocatalytical properties.

The ${ }^{14} \mathrm{C}$ mass balances of the uninoculated phenanthrene and fluoranthene controls indicate negligible abiotic losses of either compound (Table S2, Supporting Information). During active biotranformation, $\mathrm{PAH}$ depletion of the silicone after $9 \mathrm{~h}$ ranged between 1.4 and $26.3 \%$ for phenanthrene and between 0.9 and $6.1 \%$ for fluoranthene (Table S3, Supporting Information). Therefore, apart from the two lowest phenanthrene concentrations, PAH masses in the silicone decreased by less than $7 \%$. Such depletion is minor, particularly compared to the factor $10^{4}$ difference in dissolved concentrations tested. Partitioning inputs were thus considered constant, with the O-rings functioning effectively as a buffer to allow high compound turnover while slowing the decrease in dissolved concentrations. Although an important driving force in this study was to have a small silicone reservoir to minimize use of costly ${ }^{14} \mathrm{C}$ substrate, the reservoir could easily be increased to allow more compound turnover but with less depletion.

Growth of the bacteria would progressively increase the consumptive flux but can be discounted by a simple carbon mass balance. Assuming the dry weight of a bacterial cell to be $0.3 \mathrm{pg}$ and that $50 \%$ of this is carbon, ${ }^{27,28}$ initial bacterial carbon in the $1 \mathrm{~mL}$ inoculating suspension of the biodegradation experiments was $64.7 \mu \mathrm{g}$ of $\mathrm{C}$. The masses of phenanthrene or fluoranthene degraded are shown in Table S4 (Supporting Information). Assuming a yield coefficient of $0.5 \mathrm{~g}$ of PAH ( $\mathrm{g}$ of biomass $)^{-1}{ }^{29-31}$ biomass could have maximally increased by between 0.01 to $4.7 \mu \mathrm{g}$ of $\mathrm{C}$ for phenanthrene between the lowest and highest concentrations. For fluoranthene, the respective increases would have been between 0.0005 and $1.2 \mu \mathrm{g}$ of $\mathrm{C}$. For the pilot study, initial bacterial carbon was $5.2 \mu \mathrm{g}$ of $\mathrm{C}$, compared to a maximum potential increase of only $0.17 \mu \mathrm{g}$ of $\mathrm{C}$. Therefore, a significant increase in biomass, and thus also enzyme content, can be ruled out for all experiments. However, a simple solution to completely avoid growth would have been, after some washings, to suspend the cells in phosphate-buffered saline. Note that biomass can also decrease when conditions are unfavorable, e.g., when substrate turnover is insufficient for maintenance or concentrations are toxic.

Since any decrease in partitioning inputs due to depletion of the silicone was minor, and biomass did not increase significantly, steady-state dissolved concentrations during the linear 
mineralization phase were calculated by assuming constant inputs and losses using eq 6 and are shown in Table S1 (Supporting Information). In a steady-state situation, a concentration gradient exists in the aqueous $\mathrm{BL}$ adjacent to the silicone surface, and the bulk aqueous phase is homogeneous albeit with lower concentrations than equilibrium partitioning levels. Bacteria residing on the silicone surface will therefore be exposed to a concentration gradient, whereas those in suspension will experience a homogeneous dissolved environment. In this study, only $10 \%$ of the bacterial cells were found associated with the silicone surface (Figure S3, Supporting Information), and the bulk suspension steady-state dissolved concentrations are therefore the appropriate bioavailability metric. In addition to uptake from the aqueous phase, attached bacterial cells might obtain additional substrate directly from the silicone. This will depend on factors such as contact area, exchange kinetics, and enzyme saturation phenomena, but again this is likely negligible in this study because of the minor proportion of bacteria on the silicone. Nevertheless, direct substrate uptake from the polymer should always be considered.

Further Applications of Dynamic Passive Dosing in Biotransformation Studies. The dynamic passive dosing approach has potential for studying the biotransformation of hydrophobic compounds. Indeed, just recently a related polymer dosing based system has been applied for studying the in vitro biotransformation of hydrophobic chemicals by rat liver S9 homogenates. ${ }^{32}$ Here, biotransformation kinetics are calculated from the decrease in polymer and/or dissolved concentrations with reference to an inactivated control. Biotransformation rates determined with this approach were found to be 2 times higher than conventional solvent spiking.

With passive dosing cosolvent spiking is avoided, the buffering capacity of the polymer allows a high compound turnover even at very low dissolved concentrations, and with knowledge of the input and loss kinetics of the setup, these are defined even if analytical confirmation is not possible. Dissolved concentration can be controlled to any level from aqueous solubility down to zero, opening up completely new possibilities for studying biotransformation at environmentally relevant concentrations. Increased compound turnover enhances flexibility in end point choice, which might be substrate depletion, product formation, or growth. Particularly, when measuring substrate depletion, the high partitioning of hydrophobics to the polymer greatly simplifies analysis of small concentration changes.

In this study, bacterial mineralization kinetics of single HOCs were chosen to illustrate the approach. Other application areas include enzymatic biotransformations, investigating compound thresholds for cell maintenance, or gene activation and abiotic transformation reactions. Further interesting possibilities include mixture biotransformation, where by varying the compound concentrations in the polymer the dissolved concentrations of each mixture component can be independently controlled. Finally, passive dosing might be used in a simpler manner to investigate metabolic pathways. Here, compound turnover can be maximized by increasing the size of the dosing reservoir to enhance metabolite production for ease of analysis. A potential issue with silicone is attachment of the biocatalyst to the silicone surface. This might be circumvented by treating the silicone surface to reduce attachment, ${ }^{33,34}$ or alternatively, other polymers might also be considered as the dosing phase.

Particularly critical in dynamic passive dosing is the correct dimensioning, starting with sizing the polymer reservoir to achieve the required compromise between substrate depletion and end point measurement. Also important is balancing the polymer release and biotransformation kinetic, so that welldefined steady-state dissolved concentrations close to the equilibrium partitioning values can be attained for robust use as the bioavailability metric. When bulk concentrations are close to equilibrium partitioning levels, the distribution of $\mathrm{HOC}$ substrate in the aqueous phase can be considered homogeneous and the issue of attachment of the biotransforming agent to the silicone surface is less critical. This can be achieved by either increasing the delivery flux from the silicone and/or reducing biotransformation by reducing the amount of degrading cells or enzymes.

\section{ASSOCIATED CONTENT}

\section{S Supporting Information}

Tables in the Supporting Information shows the dissolved concentrations, ${ }^{14} \mathrm{C}$ mass balances, depletion of the silicone O-rings, and the masses degraded for the biodegradation experiments. Figures show the setup, O-ring release kinetics, distribution of strain EPA505 cells on the silicone surface, ${ }^{14} \mathrm{C}$ distribution from the phenanthrene pilot study, and the cumulative mineralization curves for phenanthrene and fluoranthene. Finally, full details of the chemicals and materials and O-ring loading procedure and validation are presented. This material is available free of charge via the Internet at http://pubs.acs.org.

\section{AUTHOR INFORMATION}

\section{Corresponding Author}

*Phone: +45 87158463; fax: +45 87155010; e-mail: kecsmith@ gmail.com.

\section{Notes}

The authors declare no competing financial interest.

\section{ACKNOWLEDGMENTS}

This work was funded by FP7 Collaborative Project No. 245226 MAGIC PAH-Molecular Approaches and MetaGenomic Investigations for Optimizing Clean-up of $\mathrm{PAH}$ Contaminated Sites and by the RECETO project PUBPersistence of Soil Pollutants under Various Conditions of Bioavailability. Skilled technical help by Lotte Frederiksen and Anne Grethe Holm-Jensen, particularly for the microbiological aspects, is gratefully acknowledged.

\section{REFERENCES}

(1) Alexander, M. Aging, bioavailability, and overestimation of risk from environmental pollutants. Environ. Sci. Technol. 2000, 34, 42594265.

(2) Johnsen, A. R.; Wick, L. Y.; Harms, H. Principles of microbial PAH-degradation in soil. Environ. Pollut. 2005, 133, 71-84.

(3) Han, X.; Nabb, D. L.; Mingoia, R. T.; Yang, C. H. Determination of xenobiotic intrinsic clearance in freshly isolated hepatocytes from rainbow trout (Oncorhynchus mykiss) and rat and its application in bioaccumulation assessment. Environ. Sci. Technol. 2007, 41, 32693276.

(4) Han, X.; Mingoia, R. T.; Nabb, D. L.; Yang, C. H.; Snajdr, S. I.; Hoke, R. A. Xenobiotic intrinsic clearance in freshly isolated hepatocytes from rainbow trout (Oncorhynchus mykiss): Determination of trout hepatocellularity, optimization of cell concentrations and comparison of serum and serum-free incubations. Aquat. Toxicol. 2008, 89, 11-17.

(5) Arnot, J. A.; Mackay, D.; Parkerton, T. F.; Bonnell, M. A database of fish biotransformation rates for organic chemicals. Environ. Toxicol. Chem. 2008, 27, 2263-2270. 
(6) Nishimoto, M.; Yanagida, G. K.; Stein, J. E.; Baird, W. M.; Varanasi, U. The metabolism of benzo(a)pyrene by English sole (Parophrys vetulus): Comparison between isolated hepatocytes in vitro and liver in vivo. Xenobiotica 1992, 22, 949-961.

(7) Xue, W.; Warshawsky, D. Metabolic activation of polycyclic and heterocyclic aromatic hydrocarbons and DNA damage: A review. Toxicol. Appl. Pharmacol. 2005, 206, 73-93.

(8) Lu, C.; Li, P.; Gallegos, R.; Uttamsingh, V.; Xia, C. Q.; Miwa, G. T.; Balani, S. K.; Gan, L. S. Comparison of intrinsic clearance in liver microsomes and hepatocytes from rats and humans: Evaluation of free fraction and uptake in hepatocytes. Drug Metab. Dispos. 2006, 34, 1600-1605.

(9) Desai, A. M.; Autenrieth, R. L.; Dimitriou-Christidis, P.; McDonald, T. J. Biodegradation kinetics of select polycyclic aromatic hydrocarbon (PAH) mixtures by Sphingomonas paucimobilis EPA 505. Biodegradation 2008, 19, 223-233.

(10) Wammer, K. H.; Peters, C. A. Polycyclic aromatic hydrocarbon biodegradation rates: A structure-based study. Environ. Sci. Technol. 2005, 39, 2571-2578.

(11) Dimitriou-Christidis, P.; Autenrieth, R. L.; McDonald, T. J.; Desai, A. M. Measurement of biodegradability parameters for single unsubstituted and methylated polycyclic aromatic hydrocarbons in liquid bacterial suspensions. Biotechnol. Bioeng. 2007, 97, 922-932.

(12) Wick, L. Y.; Colangelo, T.; Harms, H. Kinetics of mass transferlimited bacterial growth on solid PAHs. Environ. Sci. Technol. 2001, 35, 354-361.

(13) Brown, R. S.; Akhtar, P.; Akerman, J.; Hampel, L.; Kozin, I. S.; Villerius, L. A.; Klamer, H. J. C. Partition controlled delivery of hydrophobic substances in toxicity tests using poly(dimethylsiloxane) (PDMS) films. Environ. Sci. Technol. 2001, 35, 4097-4102.

(14) Smith, K. E. C.; Dom, N.; Blust, R.; Mayer, P. Controlling and maintaining exposure of hydrophobic organic compounds in aquatic toxicity tests by passive dosing. Aquat. Toxicol. 2010, 98, 15-24.

(15) Smith, K. E. C.; Oostingh, G. J.; Mayer, P. Passive dosing for producing defined and constant exposure of hydrophobic organic compounds during in vitro toxicity tests. Chem. Res. Toxicol. 2010, 23, $55-65$.

(16) ter Laak, T. L.; ter Bekke, M. A.; Hermens, J. L. M. Dissolved organic matter enhances transport of PAHs to aquatic organisms. Environ. Sci. Technol. 2009, 43, 7212-7217.

(17) Gouliarmou, V.; Smith, K. E. C.; de Jonge, L. W.; Mayer, P. Measuring binding and speciation of hydrophobic organic chemicals at controlled freely dissolved concentrations and without phase separation. Anal. Chem. 2012, 84, 1602-1608.

(18) Luning Prak, D. J.; Pritchard, P. H. Degradation of polycyclic aromatic hydrocarbons dissolved in Tween 80 surfactant solutions by Sphingomonas paucimobilis EPA 505. Can. J. Microbiol. 2002, 48, 151158.

(19) Johnsen, A. R.; Hausner, M.; Schnell, A.; Wuertz, S. Evaluation of fluorescently labeled lectins for noninvasive localization of extracellular polymeric substances in sphingomonas biofilms. Appl. Environ. Microbiol. 2000, 66, 3487-3491.

(20) Rusina, T. P.; Smedes, F.; Klanova, J.; Booij, K.; Holoubek, I. Polymer selection for passive sampling: A comparison of critical properties. Chemosphere 2007, 68, 1344-1351.

(21) Kwon, J. H.; Wuethrich, T.; Mayer, P.; Escher, B. I. Development of a dynamic delivery method for in vitro bioassays. Chemosphere 2009, 76, 83-90.

(22) ter Laak, T. L.; Busser, F. J. M.; Hermens, J. L. M. Poly(dimethylsiloxane) as passive sampler material for hydrophobic chemicals: Effect of chemical properties and sampler characteristics on partitioning and equilibration times. Anal. Chem. 2008, 80, 38593866.

(23) Schluep, M.; Imboden, D. M.; Galli, R.; Zeyer, J. Mechanisms affecting the dissolution of nonaqueous phase liquids into the aqueous phase in slow-stirring batch systems. Environ. Toxicol. Chem. 2001, 20, 459-466.
(24) Hayduk, W.; Laudie, H. Prediction of diffusion-coefficients for nonelectrolytes in dilute aqueous-solutions. AIChE J. 1974, 20, 611615.

(25) Levich, V. G. Physicochemical hydrodynamics; Prentice-Hall: Englewood Cliffs, NY, 1962.

(26) Harms, H.; Zehnder, A. J. B. Influence of substrate diffusion on degradation of dibenzofuran and 3-chlorodibenzofuran by attached and suspended bacteria. Appl. Environ. Microbiol. 1994, 60, 27362745.

(27) Loferer-Krössbacher, M.; Klima, J.; Psenner, R. Determination of bacterial cell dry mass by transmission electron microscopy and densitometric image analysis. Appl. Environ. Microbiol. 1998, 64, 688694.

(28) Bratbak, G.; Dundas, I. Bacterial dry-matter content and biomass estimations. Appl. Environ. Microbiol. 1984, 48, 755-757.

(29) Guha, S.; Jaffé, P. R. Determination of monod kinetic coefficients for volatile hydrophobic organic compounds. Biotechnol. Bioeng. 1996, 50, 693-699.

(30) Guha, S.; Peters, C. A.; Jaffe, P. R. Multisubstrate biodegradation kinetics of naphthalene, phenanthrene, and pyrene mixtures. Biotechnol. Bioeng. 1999, 65, 491-499.

(31) Knightes, C. D.; Peters, C. A. Aqueous phase biodegradation kinetics of $10 \mathrm{PAH}$ compounds. Environ. Eng. Sci. 2003, 20, 207-218.

(32) Lee, Y.; Otton, S. V.; Campbell, D. A.; Moore, M. M.; Kennedy, C. J.; Gobas, F. A. P. C Measuring in vitro biotransformation rates of super hydrophobic chemicals in rat liver S9 fractions using thin-film sorbent-phase dosing. Environ. Sci. Technol. 2012, 46, 410-418.

(33) Khorasani, M. T.; MoemenBellah, S.; Mirzadeh, H.; Sadatnia, B. Effect of surface charge and hydrophobicity of polyurethanes and silicone rubbers on 1929 cells response. Colloid Surf. B 2006, 51, 112119.

(34) Khorasani, M. T.; Mirzadeh, H. In vitro blood compatibility of modified PDMS surfaces as superhydrophobic and superhydrophilic materials. J. Appl. Polym. Sci. 2004, 91, 2042-2047.

\section{NOTE ADDED AFTER ASAP PUBLICATION}

Due to a production error, this paper published April 17, 2012 with errors in Figure 3, and throughout the text. The correct version published April 20, 2012. 